\title{
A Novel Plant Based Ultrasound Phantom
}

\section{Shiv Kumar Singh ${ }^{1}$, Tuhin Mistry ${ }^{2}$}

\section{Introduction}

In ultrasound guided regional anaesthesia workshops, anaesthesiologists usually concentrate on identification of nerves \& plexus on human volunteers and practice needling techniques on phantoms. Proper needle insertion technique and correct manipulation are two important skills for ultrasound-guided peripheral nerve blocks. These skills can be sharpened by practicing on ultrasound phantoms. It also helps anaesthesiologists to develop, practice and maintain the skills needed for regional anaesthesia and vascular access procedures [1]. But the use of phantoms is often limited due to the cost of blue phantom [2]. Many courses use meat-based products like turkey legs or porcine or bovine models but these may not be acceptable to everyone $[3,4]$. Vegetable based models using gelatine may not be acceptable as it is also made from animal products. We describe novel use of Aloe Vera (AV) leaves as phantom for ultrasound guided needling training. This natural AV gel-based phantom can be used for scanning, needling and practising other relevant skills. The AV phantom can be constructed from low cost, readily available natural source and is reusable.
Various materials have been used to make ultrasound training phantoms. Commercially available phantoms are expensive and homemade nerve block models are cumbersome to prepare [5]. The Aloe Vera gel is obtained from Aloe Vera plant (Aloe barbadensis miller). It is a natural product which has been used for centuries in various field specially in dermatology. Aloe Vera leaves are triangular and fleshy with serrated edges. Each leaf contains an inner clear gel which is made up of $99 \%$ water and other substances (glucomannans, amino acids, lipids, sterols and vitamins) [6]. Aloe Vera is odorless and semi-transparent unlike meatbased models.

\section{Preparing the Aloe Vera Model}

The covering of the leaves is non-echogenic and hence the pulp from Aloe Vera leaves is separated and placed in layers and covered with a Transparent Dressing(TegadermTM) film to hold them together (Fig. 1(a)). The pulp can also be placed in a container in multiple layers to create a deeper model. A thin plastic tubing or 1-0 thread is then inserted to create an echogenic shadow for depicting a nerve to practice hand-eye coordination (Fig.1 (b, c)).
Based on our routine use of this phantom, we believe it is a natural, inexpensive and effective tool for learning of ultrasoundguided peripheral nerve blocks by novices. Aloe Vera is odorless and can last for days if kept refrigerated for repeated use. The Aloe Vera model has similar consistency to that of human tissue in terms of feel and echogenicity. Such a model may be useful for those providing training at courses in ultrasound-guided peripheral nerve blocks. Our correspondence adds another indication of wide spectrum use of Aloe Vera gel and a vegan model for hand-eye coordination practice for ultrasound guided nerve blocks. We have not compared it with established phantoms or assessed their relative performances. The leaf model in fig. 1(a) appears to be small but larger phantom can be made using multiple layers for training of deeper blocks. Artificial skins as used in mannequins or even cling film can also be used instead of the plastic cover. Quantification of echogenicity of the model as compared to other models can be done in a comparative study. Since this is a vegetablebased model, it would definitely provide universality in usage.
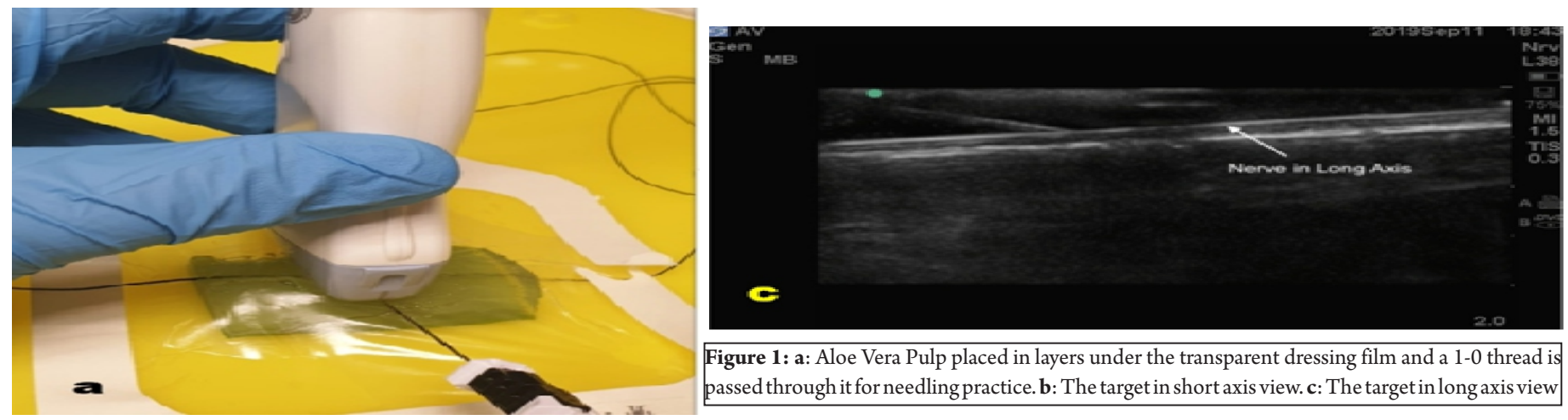

Figure 1: a: Aloe Vera Pulp placed in layers under the transparent dressing film and a 1-0 thread is passed through it for needling practice. $\mathbf{b}$ : The target in short axis view. $\mathbf{c}$ : The target in long axis view
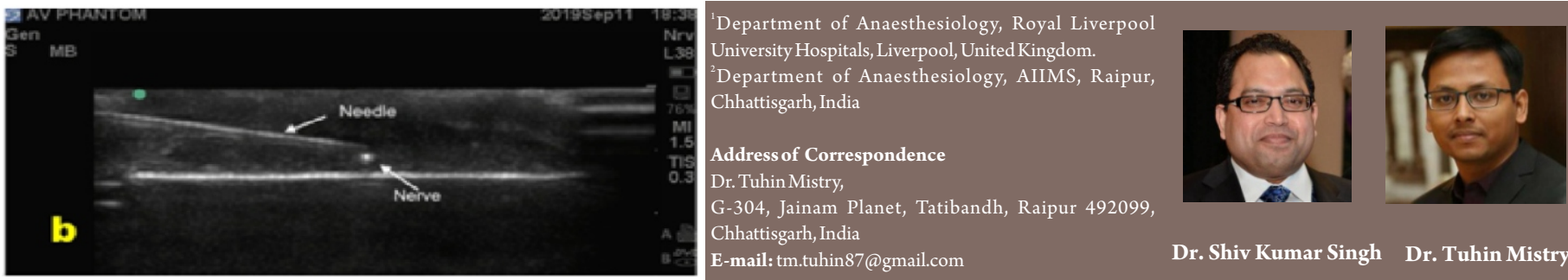

(C) 2020 by Journal of Anaesthesia and Critical Care Case Reports|Available on www.jaccr.com | DOI: 10.13107/jaccr.2020.v06i01.146 This is an Open Access article distributed under the terms of the Creative Commons Attribution Non-Commercial License (http://creativecommons.org/licenses/by-nc/3.0) which permits unrestricted non-commercial use, distribution, and reproduction in any medium, provided the original work is properly cited.

9 | Journal of Anaesthesia and Critical Care Case Reports | Volume 6 | Issue 1 | Jan-April 2020 | Page 9-10 


\section{References}

1. Sultan SF, Iohom G, Shorten G. A novel phantom for teaching and learning ultrasound-guided needle manipulation.JMed Ultrasound 2013;21:152-5.

2.https://www.bluephantom.com/category/By-Phantom-Type_Regional-Anesthesia.aspx

3. Sultan SF, Shorten G, Iohom G. Simulators for training in ultrasound guided procedures. Med Ultrason. $2013 ; 15(2): 125-131$.
4. Sparks S, Evans D, Byars D. A low cost, high fidelity nerve block model. Crit Ultrasound J. 2014;6(1):12.

5. Rathbun KM, Brader WT, Norbury JW. A simple, realistic, inexpensive nerve phantom. J Ultrasound Med 2019;38(8):2203-7.

6. Surjushe A, Vasani R, Saple DG. Aloe vera: a short review. Indian J Dermatol. 2008;53(4):163-6.

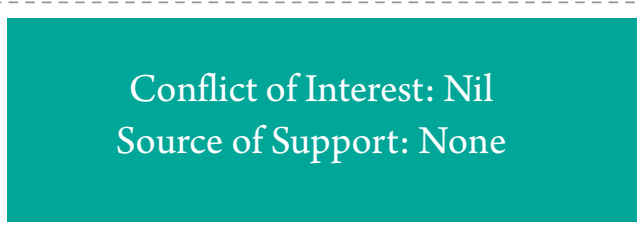

How to Cite this Article

Singh S K, Mistry T | A Novel Plant Based Ultrasound Phantom | Journal of Anaesthesia and Critical Care Case Reports | Jan-April 2020; 6(1): 9-10. 